\title{
The Impact of a Pharmacist-Conducted Interactive Anti-Smoking Education Program on the Attitudes and Knowledge of High School Students
}

\author{
Man-Tzu Marcie Wu ${ }^{1}$, Wan-Chen Shen ${ }^{1}$, Juei-Chia Chang ${ }^{1}$, Yi-Chun Chiang ${ }^{2}$, \\ Hsiang-Mei Chen ${ }^{2}$, Hsiang-Yin Chen ${ }^{2}$ \\ ${ }^{1}$ Department of Pharmacy, Taipei Medical University, Wanfang Hospital, Taipei, Chinese Taipei \\ ${ }^{2}$ School of Pharmacy, Taipei Medical University, Taipei, Chinese Taipei \\ Email: "shawn@tmu.edu.tw
}

Received April 11 $1^{\text {th }}$, 2013; revised May 12 ${ }^{\text {th }}, 2013$; accepted May $19^{\text {th }}, 2013$

\begin{abstract}
Copyright (C) 2013 Man-Tzu Marcie Wu et al. This is an open access article distributed under the Creative Commons Attribution License, which permits unrestricted use, distribution, and reproduction in any medium, provided the original work is properly cited.
\end{abstract}

\begin{abstract}
Introduction: Smoking among adolescents remains a major concern because of its long term health hazards. An effective adolescent-specific anti-smoking education is needed. Objectives: To measure the impact of a school-based tobacco prevention program provided by pharmacists on the attitudes and knowledge of senior high students. Methods: An anti-smoking program specifically aimed at high school students was developed by pharmacists and introduced to 354 students in Taiwan. It consisted of a role play and a lecture. The students were asked to complete a structural questionnaire right before and after the intervention. Results: After the intervention, the average of the total attitude scores increased from 41.7 to $43.2(\mathrm{p}=0.001)$, and the total knowledge scores increased from 6.4 to $8.2(\mathrm{p}<0.001)$. The average practice score was 31.2 (maximum score $=50$ ) and the result suggested that the practice score was associated with attitude rather than knowledge. Conclusion: This pharmacist-conducted anti-smoking program for high school students resulted in positive changes regarding both attitude and knowledge. This suggests that further anti-smoking programs targeting students would be effective in helping to prevent youth smoking.
\end{abstract}

Keywords: Attitude; High School; Smoking Cessation; Questionnaire; Education

\section{Introduction}

Adolescent smoking has a huge impact on global health and imposes a burden on the economy ("Curbing the epidemic: governments and the economics of tobacco control. The World Bank", 1999; Preventing tobacco use among young people. A report of the Surgeon General. Executive summary", 1994). The smoking rate among adults in Taiwan has declined, while in contrast the smoking rate among young people has risen (Taiwan Tobacco Control 2009 Annual Report, 2009). Studies indicated that many students had their first experience of smoking in the $5^{\text {th }}$ and $6^{\text {th }}$ grade of elementary school (Escobedo, Anda, Smith, Remington, \& Mast, 1990; Minagawa, et al., 1992). In Taiwan, $23.2 \%$ of ever-smoking high school students started smoking before reaching the age of 10 (Taiwan Tobacco Control 2009 Annual Report, 2009). The earlier a youth begins using tobacco, the more likely it is that they will continue the habit into adulthood and that it will influence their entire life (Jackson \& Dickinson, 2004; Khuder, Dayal, \& Mutgi, 1999). Tobacco is classified as "Gateway" drug and research has shown that teens between 13 and 17 years of age

${ }^{*}$ Conflict of Interest: This study was supported in part by grant no. 101wfeva-09 from Taipei Medical University-Wan Fang Hospital, Taiwan. The authors bear all responsibility and have no conflicts of interest with regard to this work.

${ }^{\#}$ Corresponding author. who smoke daily are more likely to use other drugs/substances, including alcohol, marijuana and cocaine (Summary of Findings from the 1998 National Household Survey on Drug Abuse, 1999; Takakura \& Wake, 2003). Smoking harms nearly every organ of the body, causing both short-term and long-term effects (Fagerstrom, 2002). It accounted for an estimated 443,000 deaths, or nearly 1 of every 5 deaths annually in the United States, and more than 18,800 deaths a year in Taiwan. In this context it can be seen that reducing the adolescent smoking rate is a paramount task in nourishing the younger generation (Lynch \& Bonnie, 1994).

Understanding the mentality which leads to adolescent smoking is essential in order to design an effective anti-smoking program and escape its harmful consequences. Studies have demonstrated that peer effects, curiosity, anxiety and a feeling of maturity are important determinants of smoking (Ali \& Dwyer, 2009; Wang, Fitzhugh, Westerfield, \& Eddy, 1995). The 2009 Youth Tobacco Use Survey in Taiwan also showed similar results (Taiwan Tobacco Control 2009 Annual Report, 2009). It revealed that $41.2 \%$ of senior and vocational high school students had smoked. This figure included $10 \%$ who reported being motivated by peer pressure and $10.8 \%$ who said they used tobacco for stress relief. Almost half (47\%) of teen smokers first acquired cigarettes from their classmates or friends (Taiwan Tobacco Control 2009 Annual Report, 2009). This indi- 
cates the accessibility of cigarettes through companionship and underscores the importance of preventing smoking on campus. An effective adolescent-specific anti-smoking education needs to provide a fundamental resolution to prevent smoking in adolescents.

Smoking is the leading preventable cause of death, and health is the most commonly stated primary and overall reason for wanting to quit (Aung, Hickman, \& Moolchan, 2003). As well-trained health care professionals, pharmacists can be persuasive in educating teens about the long-term effects of smoking. The current program, with its attempt to create more interactive and effective questioning, discussion and learning, was designed to measure the impact of a school-based tobacco prevention program provided by pharmacists on the attitudes and knowledge of senior high students.

\section{Materials and Methods}

The anti-smoking education program conducted by pharmacists from Taipei Medical University Wan-Fang Hospital was implemented in four senior high schools (Wan-Fang, ZhongLung, Lih-Ren, and Blessed Imelda's senior high school) in one of their military training classes from Sep. 2005 to Nov. 2005. All students participated in these classes were included into the study. The program was composed of two educational models: a drama and a lecture. The drama with role-playing scenes was used to prepare students for social situations and centered on how to resist peer pressure and to practice straightforward and simple refusal skills. The lecture contained 3 main aspects: (1) the physical effects and disadvantages of smoking, (2) the importance of smoking cessation, and (3) ways to cope with stress (Table 1). The disadvantages focused on were risks that might most concern young people: the staining of teeth and nails, premature aging, and smoker's breath. However, other important smoking-related health issues like chronic lung disease, cardiovascular diseases and cancers were also addressed. The participants were asked to provide their demographic information and complete the questionnaires before and after the program. The total scores of the responses to the knowledge and attitude questions were analyzed to evaluate the efficacy of the program.

Table 1.

Program materials and the schedule.

\begin{tabular}{ll}
\hline Materials & \multicolumn{1}{c}{ Outline } \\
\hline $\begin{array}{l}\text { Script for Role } \\
\text { play }\end{array}$ & $\begin{array}{l}\text { Peer-pressure scenario: how to resist peer-pressure } \\
\text { and practice refusal skills. }\end{array}$ \\
& $\begin{array}{l}\text { 1. Tobacco related illness } \\
\text { - }\end{array}$ \\
& $-\quad$ Tar, nicotine, carbon monoxide and carcinogens. \\
& $-\quad$ Chronic diseases. \\
$\begin{array}{l}\text { PowerPoint } \\
\text { presentation } \\
\text { lectured by the } \\
\text { pharmacists }\end{array}$ & $-\quad$ Lenefit of smoking cessation \\
& $-\quad$ ease, stroke, and peripheral vascular disease. \\
& infertility.
\end{tabular}

Schedule of the anti-smoking education program

1. September 28th, 2005: Wan-Fang senior high school

2. October 5th, 2005: Zhong-Lung senior high school

3. October 17th, 2005: Lih-Ren senior high school

4. November 14th, 2005: Blessed Imelda's senior high school

\section{Questionnaire Development}

The surveillance questionnaire was developed and modified from previously published literature (Hsia \& Spruijt-Metz, 2003; Meier, 1991). The pre- and post-intervention questionnaires differed only in the practice section, which was exclusive to the pre-intervention test. The contents were validated by three experts who majored in nursing, clinical pharmacy, and public health. The test-retest was given to 40 senior high school students to check reliability, which resulted in Spearman's rho coefficients of $0.709,0.805$, and 0.715 for attitude, practice, and knowledge respectively. The internal consistency values, using Cronbach Alpha, were 0.558, 0.815 and 0.546 for knowledge, attitude and practice items.

Knowledge Test. The knowledge questionnaire contained 10 questions to test the students' general knowledge of tobacco, common myths surrounding smoking, and the health consequences of smoking (Table 2). Each item had 3 alternatives: true, false and unknown. Scores were calculated as the sum of correct answers, with 10 being the highest possible score.

Attitude Measures. The attitude questionnaire comprised of 10 questions with responses given on a five-point scale to measure attitudes towards personal, social and environmental aspects of tobacco use (Table 2). The highest possible score was 50 and the lowest was 10 . Higher scores represented a more positive attitude about avoiding cigarette smoking.

Practice Evaluation. The 10 items in this evaluation were related to the behavior of the students over the previous six months (Table 3). Each item was scored on a five-point scale, with the lowest possible score being 10 and the highest 50 . Higher scores represented better practice in supporting antismoking activities.

\section{Statistical Analyses}

Spearman's correlation was used to identify test and re-test reliability as well as the correlations regarding the attitude, practice and knowledge scores. The Wilcoxon signed-rank test was used to analyze the differences in the correct rates of knowledge and attitude. All statistical tests were computed using the Statistical Package for Social Science (SPSS 13.0, SPSS Inc, Chicago, IL, USA) with significance defined as $\mathrm{p}<0.05$. Because the questionnaires were anonymous, two-sample ttests were used instead of paired t-tests.

\section{Results}

A total of 354 students participated in the education program, and $304(86 \%)$ students completed and returned both the preintervention and post-intervention questionnaires. The demographic data of the students can be seen in Table 4. Female students were predominant, $208(68.4 \%)$, due to the fact that the Blessed Imelda Senior High School is a girls' high school. Comparing to male students, female students had higher total attitude scores $(40.1 \pm 6.39$ vs. $42.5 \pm 5.8, \mathrm{P}=0.002)$ and total practice scores $(29.45 \pm 4.4$ vs. $32.03 \pm 3.89, \mathrm{P}<0.001)$. There were no significant differences in total knowledge scores between males and females $(6.51 \pm 2.15$ vs. $6.3 \pm 1.86, \mathrm{P}=$ $0.238)$.

More than half the participants (184 students, 60.5\%) had family members with smoking habits, $37(12.2 \%)$ had some experience of smoking, and $4(1.3 \%)$ were regular smokers (Table 4). Before the intervention, the total knowledge and attitude 
Table 2.

Knowledge and attitude scores: impact of the intervention.

\begin{tabular}{|c|c|c|c|c|}
\hline Categories & Items & Pre-intervention & Post-intervention & P-value \\
\hline \multicolumn{5}{|l|}{ Knowledge } \\
\hline Common myth of smoking & 3 & $2.17 \pm 0.71$ & $2.78 \pm 0.62$ & $<0.001$ \\
\hline Smoking with a filter can minimize health damages & & $0.79 \pm 0.40$ & $0.96 \pm 0.20$ & $<0.001$ \\
\hline Inhaling second-hand smoke does no harm to our health & & $0.97 \pm 0.16$ & $0.92 \pm 0.26$ & 0.005 \\
\hline Light or mint cigarettes do less harm to our bodies than general ones do & & $0.41 \pm 0.49$ & $0.89 \pm 0.31$ & $<0.001$ \\
\hline General knowledge of tobacco & 2 & $0.68 \pm 0.73$ & $1.02 \pm 0.75$ & $<0.001$ \\
\hline There is cholesterol in cigarettes & & $0.27 \pm 0.44$ & $0.47 \pm 0.50$ & $<0.001$ \\
\hline Tar is the main substrate that causes tobacco addiction & & $0.41 \pm 0.49$ & $0.55 \pm 0.50$ & $<0.001$ \\
\hline Health consequences & 5 & $3.52 \pm 1.36$ & $4.43 \pm 0.97$ & $<0.001$ \\
\hline Oral cavity cancer is unrelated to smoking & & $0.79 \pm 0.41$ & $0.94 \pm 0.24$ & $<0.001$ \\
\hline Gastrointestinal ulcers are unrelated to smoking & & $0.68 \pm 0.47$ & $0.89 \pm 0.31$ & $<0.001$ \\
\hline Smoking will affect efficacy of some medications (e.g. contraceptives) & & $0.61 \pm 0.49$ & $0.77 \pm 0.42$ & $<0.001$ \\
\hline Smoking will interfere with the menstrual cycle & & $0.68 \pm 0.47$ & $0.91 \pm 0.29$ & $<0.001$ \\
\hline Pregnant women who smoke will easily give birth to underweight babies & & $0.76 \pm 0.43$ & $0.93 \pm 0.26$ & $<0.001$ \\
\hline Total & 10 & $6.37 \pm 1.95$ & $8.24 \pm 1.63$ & $<0.001$ \\
\hline \multicolumn{5}{|l|}{ Attitude } \\
\hline Personal aspect & 3 & $8.73 \pm 2.62$ & $9.35 \pm 2.76$ & 0.002 \\
\hline 1. Smoking can keep up one's spirits & & $2.81 \pm 1.10$ & $2.98 \pm 1.19$ & 0.048 \\
\hline 2. Smoking can make one feel relaxed & & $2.75 \pm 1.12$ & $3.01 \pm 1.20$ & 0.002 \\
\hline 3. Smoking is a tool to control body weight & & $3.18 \pm 0.98$ & $3.37 \pm 0.96$ & 0.019 \\
\hline Social aspect & 4 & $14.11 \pm 2.37$ & $14.56 \pm 2.17$ & 0.005 \\
\hline 4. People can make friends through smoking & & $3.45 \pm 0.80$ & $3.63 \pm 0.67$ & 0.002 \\
\hline 5. Smoking is a symbol of maturity & & $3.53 \pm 0.76$ & $3.67 \pm 0.68$ & 0.009 \\
\hline 6. Smoking can make me look cool & & $3.40 \pm 0.86$ & $3.70 \pm 0.62$ & $<0.001$ \\
\hline 7. Smoking may affect others' health & & $3.72 \pm 0.74$ & $3.57 \pm 1.03$ & 0.04 \\
\hline Environmental aspect & 3 & $8.88 \pm 2.51$ & $9.27 \pm 2.91$ & 0.029 \\
\hline 8. Smoking should be forbidden in all internet café and KTV & & $3.07 \pm 1.11$ & $3.11 \pm 1.26$ & 0.559 \\
\hline 9. Cigarette smells make people uncomfortable & & $3.34 \pm 1.16$ & $3.42 \pm 1.12$ & 0.412 \\
\hline 10. Advertisements of tobacco should be forbidden & & $2.46 \pm 1.23$ & $2.73 \pm 1.25$ & 0.004 \\
\hline Total & 10 & $31.71 \pm 6.06$ & $33.18 \pm 5.83$ & 0.001 \\
\hline
\end{tabular}

(1) Knowledge scores were calculated as the sum of correct answers, with 10 being the highest possible score; (2) Five point scale for attitude $\# 7,8,9,10: 5=$ strongly agree, 4 = agree, 3 = neither agree nor disagree (neutral response), 2 = disagree, 1 = strongly disagree; (3) Five point scale for attitude \#1, 2, 3, 4, 5, 6:5= strongly disagree, 4 = disagree, 3 = neither agree nor disagree (neutral response), 2 = agree, 1 = strongly agree; (4) Higher attitude scores represented a more positive attitude about avoiding cigarette smoking. 
Table 3.

Practice: pre-intervention scores.

\begin{tabular}{lcc}
\hline Categories & Items & Pre-intervention \\
\hline Personal aspect & 3 & $4.88 \pm 1.47$ \\
1. I reported stores selling tobacco to teenagers & $0.18 \pm 0.54$ \\
2. I bought cigarettes for my family, friends or myself & $3.68 \pm 0.73$ \\
3. I joined educational anti-smoking campaigns & $1.01 \pm 1.03$ \\
Social aspect & $41.03 \pm 2.48$ \\
4. I dissuaded my family and relatives from smoking & $1.79 \pm 1.39$ \\
5. I dissuaded my classmates or friends who are nonage from smoking & $1.55 \pm 1.33$ \\
6. My relatives or friends have asked me to smoke & $3.84 \pm 0.47$ \\
7. I said yes when other people asked me to smoke & $3.84 \pm 0.58$ \\
Environmental aspect & 3 \\
8. I dissuaded strangers from smoking in the non-smoking area & $5.29 \pm 1.87$ \\
9. I prefer to go to smoke-free public places & $0.37 \pm 0.67$ \\
10. I have been to places where a lot of people smoke (e.g. Karaoke, pub etc.) & $2.24 \pm 1.22$ \\
Total & 10 & $2.69 \pm 1.02$ \\
\hline
\end{tabular}

(1) Five point scale for \#2,6,7,10: 1 = always, $2=$ usually, $3=$ sometimes, $4=$ seldom, $5=$ never; (2) Five point scale for \#1, 3, 4, 5, 8, 9: $1=$ never, $2=$ seldom, $3=$ sometimes, 4 = usually, 5 = always; (3) Higher scores represented better practice in supporting anti-smoking activities.

Table 4.

Demographic data of enrolled students.

\begin{tabular}{lc}
\hline Demographic characters & Number (\%) \\
\hline Grade & $220(72.3)$ \\
11 th & $84(27.6)$ \\
12 th & \\
Gender & $96(31.5)$ \\
Male & $208(68.4)$ \\
Female & \\
Do any members of your family smoke? & $184(60.5)$ \\
Yes & $120(39.4)$ \\
No & \\
Have you ever smoked? & $4(1.3)$ \\
Yes, and I have smoking habit. & $37(12.2)$ \\
Yes, but I don't have a smoking habit. & $263(86.5)$ \\
No.
\end{tabular}

scores between groups of students with and without family smokers had no significant difference (both $\mathrm{P}>0.05$ ). However, the practice scores of students with family smokers were significantly higher in social aspect $(15.45 \pm 8.0$ vs. $14.76 \pm 2.5, \mathrm{P}$ $<0.012)$ but lower $(7.9 \pm 2.0$ vs. $8.5 \pm 1.8, \mathrm{P}<0.004)$ in environmental aspect compared to students without family smokers (Table 5).

The education program improved the students' knowledge of issues surrounding smoking remarkably, with the average total score increasing from $6.37 \pm 1.95$ to $8.24 \pm 1.63$ (maximum score $=10, p<0.001)$ (Table 2). In the post-intervention questionnaire, question \#4 (There is cholesterol in cigarettes) had the lowest percentage of correct answers $(47.97 \%)$ and question \#1 (Smoking with a filter can minimize health damages) had the highest (96.96\%).

The mean post-intervention attitude score was 1.47 points higher than that of the pre-intervention, the scores being 31.71 \pm 6.06 and $33.18 \pm 5.83$ respectively (maximum score $=50, \mathrm{p}<$ 0.05) (Table 2). Question \#7 (Smoking may affect others' health) was the only one that failed to show a significant improvement following the education program (4.71 \pm 0.77 vs. $4.59 \pm 0.99, p=0.097)$. However, this is because the baseline attitude score was already high.

The results of the practice section established that the students had very low rates of participation in anti-smoking activities (Table 3). About $25 \%$ of the students didn't conform to the legal prohibition on buying cigarettes when under 18 years of age and only $0.3 \%, 15.9 \%$ and $10.8 \%$ of students reported that they always dissuaded strangers, family and friends from smoking. It was also found that about $87 \%$ of the students fail to report illegal selling. Moreover, high school students did not actively support anti-smoking programs, which was indicated by more than one third of the students (39.2\%) never having participated in educational anti-smoking campaigns.

A linear positive correlation was found between attitude and practice (correlation coefficient $=0.329, \mathrm{P}<0.005$ ). However, no correlations were found between levels of knowledge and attitude or practice.

\section{Discussion}

The possibility of a pharmacist-initiated education program having a positive impact was confirmed by this study, which showed significant improvements in both students' knowledge and attitudes toward smoking. The pre-intervention data indicated that students' knowledge and attitudes were less than satisfactory and that educational efforts were needed to correct inaccuracies in their understanding of the subject. Additionally, the practice assessment demonstrated poor general practice regarding anti-smoking activities (Table 3). Whilst over $70 \%$ of the students were aware of the health consequences of the smo- 
Table 5.

Difference between groups with family smokers or not prior to the intervention. Mann-Whitney test.

\begin{tabular}{|c|c|c|c|c|}
\hline Categories & Items & No family smokers (184) & With family smokers (120) & P-value \\
\hline \multicolumn{5}{|l|}{ Knowledge } \\
\hline Common myth of smoking & 3 & $2.21 \pm 0.73$ & $2.11 \pm 0.68$ & 0.176 \\
\hline General knowledge of tobacco & 2 & $0.63 \pm 0.76$ & $0.75 \pm 0.75$ & 0.150 \\
\hline Health consequences & 5 & $3.58 \pm 1.36$ & $3.43 \pm 1.35$ & 0.262 \\
\hline Total scores & 10 & $6.42 \pm 1.97$ & $6.28 \pm 1.92$ & 0.492 \\
\hline \multicolumn{5}{|l|}{ Attitude } \\
\hline Personal aspect & 3 & $11.76 \pm 2.65$ & $11.7 \pm 2.58$ & 0.393 \\
\hline Social aspect & 4 & $17.97 \pm 2.52$ & $18.3 \pm 2.1$ & 0.699 \\
\hline Environmental aspect & 3 & $11.75 \pm 2.56$ & $12.1 \pm 2.43$ & 0.347 \\
\hline Total scores & 10 & $41.49 \pm 6.19$ & $42.0 \pm 5.8$ & 0.517 \\
\hline \multicolumn{5}{|l|}{ Practice } \\
\hline Personal aspect & 3 & $7.92 \pm 1.32$ & $7.81 \pm 1.68$ & 0.529 \\
\hline Social aspect & 4 & $14.76 \pm 2.5$ & $15.45 \pm 8.0$ & $\mathrm{P}<0.012$ \\
\hline Environmental aspect & 3 & $8.5 \pm 1.8$ & $7.9 \pm 2.0$ & $\mathrm{P}<0.004$ \\
\hline Total scores & 10 & $31.2 \pm 4.9$ & $31.2 \pm 4.5$ & 0.914 \\
\hline
\end{tabular}

king, they did not actively try to persuade their family or friends from smoking or report stores for selling cigarettes illegally to teenagers under 18 years of age. What could be described as passive and conservative behavior in Taiwanese senior high school students regarding anti-smoking was observed, which further emphasizes the importance of making efforts towards tobacco hazard prevention on campuses.

A mild-to-moderate positive correlation was found between attitudes and practice. This supports the theory of attitude-behavior relations discussed in previous studies (Ajzen, 2001). However, this study showed no correlation between knowledge and practice, which suggests that knowledge of smoking does not guarantee good practice. This finding is also in accordance with the results of other studies demonstrating a low correlation between smoking-related knowledge and behavior (Hodgetts, Broers, \& Godwin, 2004; Torabi, Yang, \& Li, 2002). In the present study, the mean score of the knowledge assessment improved by $28 \%$ following the education program, with the attitude assessment rising by $3.6 \%$. Although both improvements were statistically significant, this indicates that attitude may be much more difficult to influence. This was also demonstrated by the "Start to stop" survey conducted in Memphis, United States, which examined the effectiveness of a school-based smoking cessation program among students caught smoking at school (Robinson, Vander Weg, Riedel, Klesges, \& McLainAllen, 2003). It showed a significant improvement in tobacco-related knowledge but left attitudes unchanged. So whilst an educational program might well be able to raise the level of knowledge successfully, it does not follow that this will result in improved practice.

Not all types of education program are successful, and studies have indicated that programs using cognitive-behavioral techniques or strategies to enhance motivation lead to significantly higher cessation rates (Sussman, Sun, \& Dent, 2006). The present study program attempted to enhance students' understanding by acting out the consequences of smoking and a scenario of what to do when tempted to smoke. It aimed to help students identify the social and physical consequences of smoking and develop their ability to resist peer pressure. The introduction of cigarette refusal skills, one of which is coping with peer pressure, has been found to be a successful component in smoking prevention programs (Nabors, Iobst, \& McGrady, 2007). Besides the professional image pharmacists bring, using a different teaching technique other than simply doing a powerpoint style lecture might also have played a role in the success of the study.

One of the main limitations of this study was its short-term design as there was no follow-up surveillance to assess the long-term impact of improved attitude on students' behavior. Also, to include a control group in the future that does not get an intervention or that gets just a power point presentation not also the role playing should provide a better evidence of the effect of the intervention. Besides, due to the nature of the survey, it should be recognized that students might have underestimated their tobacco use status. The high proportion of female participants may also have an impact on the low ever-smoking rate in this study $(12.2 \%$ in this study vs. $41.2 \%$ in Youth Tobacco Use Survey in Taiwan). However, the results of the study did provide some feedback which can be used to improve future programs. Different strategies focusing on enhancing active learning should be developed to further improve attitude, as it is suggested that changes in attitude rather than increased knowledge is the key to modifying behavior.

The current study also showed an interesting result indicating that students with family members who smoked were more willing to dissuade family and friends from smoking but cared less about going to places where a lot of people smoke (Table 5, Practice). It suggested that students who had family smokers had more opportunities and felt more comfortable asking people to quit, however, they tended to be less sensitive to the environmental tobacco smoke. Previous studies indicated that smoking within families was a key influence to youth smoking (Hill, Hawkins, Catalano, Abbott, \& Guo, 2005; Keyes, Legrand, Iacono, \& McGue, 2008), together with our results, this group of stu- 
dents could become important members to be enrolled when we involve high school education into future anti-smoking projects.

\section{Conclusion}

This study demonstrated the efficacy of the school-based anti-smoking education program was developed by pharmacists. It also showed that health care professionals such as pharmacists can have a positive influence on high school students' attitudes towards smoking and increase their knowledge of the issues involved. Additionally, the attitude-behavior relationship was confirmed by the study. However, future efforts with continued follow-up may be needed to further evaluate the longterm impact of the program.

\section{REFERENCES}

Ajzen, I. (2001). Nature and operation of attitudes. Annual Review of Psychology, 52, 27-58. doi:10.1146/annurev.psych.52.1.27

Ali, M. M., \& Dwyer, D. S. (2009). Estimating peer effects in adolescent smoking behavior: A longitudinal analysis. Journal of Adolescent Health, 45, 402-408. doi:10.1016/j.jadohealth.2009.02.004

Aung, A. T., Hickman, N. J., \& Moolchan, E. T. (2003). Health and performance related reasons for wanting to quit: Gender differences among teen smokers. Substance Use \& Misuse, 38, 1095-1107. doi:10.1081/JA-120017652

The World Bank (1999). Curbing the epidemic: Governments and the economics of tobacco control. Tob Control, 8, 196-201.

Escobedo, L. G., Anda, R. F., Smith, P. F., Remington, P. L., \& Mast, E. E. (1990). Sociodemographic characteristics of cigarette smoking initiation in the United States. Implications for smoking prevention policy. JAMA, 264, 1550-1555. doi:10.1001/jama.1990.03450120062030

Fagerstrom, K. (2002). The epidemiology of smoking: Health consequences and benefits of cessation. Drugs, 62, 1-9. doi:10.2165/00003495-200262002-00001

Hill, K. G., Hawkins, J. D., Catalano, R. F., Abbott, R. D., \& Guo, J. (2005). Family influences on the risk of daily smoking initiation. Journal of Adolescent Health, 37, 202-210. doi:10.1016/j.jadohealth.2004.08.014

Hodgetts, G., Broers, T., \& Godwin, M. (2004). Smoking behaviour, knowledge and attitudes among Family Medicine physicians and nurses in Bosnia and Herzegovina. BMC Family Practice, 5, 12. doi:10.1186/1471-2296-5-12

Hsia, F. N., \& Spruijt-Metz, D. (2003). The meanings of smoking among Chinese American and Taiwanese American college students. Nicotine \& Tobacco Research, 5, 837-850. doi:10.1080/14622200310001615259

Jackson, C., \& Dickinson, D. (2004). Cigarette consumption during childhood and persistence of smoking through adolescence. Archives of Pediatrics \& Adolescent Medicine, 158, 1050-1056. doi:10.1001/archpedi.158.11.1050

Keyes, M., Legrand, L. N., Iacono, W. G., \& McGue, M. (2008). Parental smoking and adolescent problem behavior: An adoption study of general and specific effects. American Journal of Psychiatry, 165, 1338-1344. doi:10.1176/appi.ajp.2008.08010125

Khuder, S. A., Dayal, H. H., \& Mutgi, A. B. (1999). Age at smoking onset and its effect on smoking cessation. Addictive Behaviors, 24, 673-677. doi:10.1016/S0306-4603(98)00113-0

Lynch, B. S., \& Bonnie, R. J. (1994). Growing up tobacco free: Preventing nicotine addiction in children and youths. National Academy Press, 1.

Meier, K. S. (1991). Tobacco truths: the impact of role models on children's attitudes toward smoking. Health Education Quarterly, 18, 173-182. doi:10.1177/109019819101800203

Minagawa, K.-E., Nishioka, N., Kawabata, T., Takahashi, H., MOChizuki, Y., Nozu, Y., et al. (1992). Tobacco use among Japanese school children: results from preliminary study of Japan adolescent smoking survey (JASS). Health Promotion International, 7, 8. doi:10.1093/heapro/7.1.37

Nabors, L., Iobst, E. A., \& McGrady, M. E. (2007). Evaluation of schoolbased smoking prevention programs. The Journal of School Health, 77, 331-333. doi:10.1111/j.1746-1561.2007.00215.x

Executive Summary (1994). Preventing tobacco use among young people. A report of the surgeon general. The MMWR Recommendations and Reports, 43, 1-10.

Robinson, L. A., Vander Weg, M. W., Riedel, B. W., Klesges, R. C., \& McLain-Allen, B. (2003). "Start to stop": Results of a randomised controlled trial of a smoking cessation programme for teens. Tob Control, 12, IV26-IV33. doi:10.1136/tc.12.suppl 4.iv26

Summary of Findings from the 1998 National Household Survey on Drug Abuse (1999). Substance abuse and mental health services administration. US Department of Health and Human Services.

Sussman, S., Sun, P., \& Dent, C. W. (2006). A meta-analysis of teen cigarette smoking cessation. Health Psychology, 25, 549-557. doi:10.1037/0278-6133.25.5.549

Taiwan Tobacco Control 2009 Annual Report (2009). Bureau of Health Promotion. Chinese Tapei: Department of Health.

Takakura, M., \& Wake, N. (2003). Association of age at onset of cigarette and alcohol use with subsequent smoking and drinking patterns among Japanese high school students. The Journal of School Health, 73, 226-231. doi:10.1111/j.1746-1561.2003.tb06566.x

Torabi, M. R., Yang, J., \& Li, J. (2002). Comparison of tobacco use knowledge, attitude and practice among college students in China and the United States. Health Promotion International, 17, 247-253. doi:10.1093/heapro/17.3.247

Wang, M. Q., Fitzhugh, E. C., Westerfield, R. C., \& Eddy, J. M. (1995). Family and peer influences on smoking behavior among American adolescents: An age trend. Journal of Adolescent Health, 16, 200203. doi:10.1016/1054-139X(94)00097-X 


\section{Appendix}

Smoking Cessation questionnaire in Mandarin

\begin{tabular}{|c|c|c|}
\hline Grade: & $\square$ Second Year $\left(11^{\text {th }}\right.$ Grade $)$ & $\square$ Third year $\left(12^{\text {th }}\right.$ Grade $)$ \\
\hline Gender: & $\square$ Male & $\square$ Female \\
\hline Do you have relatives who smoke? & $\square$ No & $\begin{array}{l}\square \text { Yes. } \\
\text { Who? } \\
\text { (e.g. mom, dad, brothers, etc }\end{array}$ \\
\hline
\end{tabular}

Please mark one of the following that best describes your situation.

(e.g. mom, dad, brothers, etc.)

$$
\begin{aligned}
& \square \mathrm{I} \text { smoke_cigarettes per day } \\
& \square \mathrm{I} \text { had smoked before, but I am not a regular smoker. } \\
& \square \mathrm{I} \text { have never smoked before. } \\
& \text { Are you anticipated to try smoking in } 6 \text { months? } \\
& \square \text { Yes } \quad \square \text { No }
\end{aligned}
$$

Part 1: Please mark the most suitable answer.

K1. Smoking with a filter can avoid health damage

$\mathrm{K} 2$. Oral cavity cancer is unrelated to smoking

K3. Gastrointestinal ulcers are unrelated to smoking.

$\mathrm{K} 4$. There is cholesterol in cigarettes

$\mathrm{K} 5$. Inhaling secondhand smoke is not real smoking, so it does no harm to our health

K6. Smoking will affect efficacy of some medications (e.g. contraceptives)

$\mathrm{K} 7$. Tar is the main substrate for tobacco addiction

K8. Light or mint cigarettes do less harm to our bodies than general ones do

K9. Smoking will interfere with the menstrual cycle

K10. Pregnant women who smoke will easily give birth to light-weight babies

Part 2: Please mark the item that best expresses your opinion. In general, I believe that:

1. Smoking can keep up one's spirits

2. People can make friends through smoking

3. Smoking is a symbol of maturity

4. Smoking should be forbidden in all internet café and KTV

5. Smoking can make one feel relaxed

6. Cigarette smells make people uncomfortable

7. Advertisements of tobacco should be forbidden

8. Smoking can make me look cool

9. Smoking is a method to control body weight

10. Smoking may affect others' health

Part 3: Please mark the frequency of facing the situations below.

Always: 90\% Usually: $75 \%$ Sometimes: $50 \%$ Seldom: $25 \%$ Never: $0 \%$

In the half passed year...

P1. I dissuaded strangers from smoking in the non-smoking area

P2. I dissuaded my family and relatives from smoking

P3. I dissuaded my classmates or friends who are nonage from smoking

P4. I reported stores selling tobacco to teenagers

P5. I bought tobacco for my family, friends or myself

\begin{tabular}{|c|c|c|c|c|}
\hline $\begin{array}{c}\text { Strongly } \\
\text { Agree }\end{array}$ & Agree & No Comments & Disagree & Strongly Disagree \\
\hline 口 & $\square$ & 口 & 口 & 口 \\
\hline 口 & $\square$ & $\square$ & 口 & 口 \\
\hline$\square$ & $\square$ & $\square$ & $\square$ & 口 \\
\hline 口 & $\square$ & $\square$ & 口 & $\square$ \\
\hline$\square$ & $\square$ & $\square$ & 口 & $\square$ \\
\hline 口 & 口 & 口 & 口 & 口 \\
\hline$\square$ & $\square$ & 口 & $\square$ & $\square$ \\
\hline$\square$ & $\square$ & $\square$ & $\square$ & $\square$ \\
\hline$\square$ & $\square$ & $\square$ & $\square$ & $\square$ \\
\hline 口 & $\square$ & $\square$ & $\square$ & $\square$ \\
\hline Never & Seldom & Sometimes & Usually & Always \\
\hline$\square$ & $\square$ & $\square$ & $\square$ & $\square$ \\
\hline 口 & 口 & $\square$ & $\square$ & $\square$ \\
\hline$\square$ & $\square$ & $\square$ & $\square$ & $\square$ \\
\hline 口 & 口 & $\square$ & $\square$ & 口 \\
\hline 口 & 口 & $\square$ & 口 & $\square$ \\
\hline$\square$ & $\square$ & $\square$ & $\square$ & $\square$ \\
\hline$\square$ & $\square$ & $\square$ & $\square$ & $\square$ \\
\hline$\square$ & $\square$ & $\square$ & $\square$ & $\square$ \\
\hline$\square$ & $\square$ & $\square$ & $\square$ & 口 \\
\hline 口 & 口 & $\square$ & $\square$ & 口 \\
\hline
\end{tabular}

P6. My relatives or friends have asked me to smoke

P7. I said yes when other people asked me to smoke

P8. I joined educational anti-smoking campaigns

P9. I prefer to go to smoke-free public places.

P10. I have been to places where a lot of people smoke (e.g. KTV, pub etc.) 